\title{
Consumo, avaliação do modelo small ruminant nutrition system e predição da composição corporal de cordeiros Santa Inês alimentados com rações contendo diferentes níveis de energia ${ }^{1}$
}

\section{Intake, evaluation of small ruminant nutrition system model and prediction of body composition of Santa Ines lambs fed diets with different levels of energy}

\author{
Iana Sérvulo Gomes Maia²; Elzânia Sales Pereira ${ }^{3}$; Andréa Pereira Pinto ${ }^{4 *}$; \\ Ivone Yurika Mizubuti; ; Edson Luis de Azambuja Ribeiro; \\ Maria Socorro de Souza Carneiro ${ }^{4}$; Ana Cláudia Nascimento Campos ${ }^{4}$; \\ Carla Renata Figueiredo Gadelha ${ }^{4}$; José Nery Rocha Júnior ${ }^{6}$
}

Resumo

\begin{abstract}
Objetivou-se avaliar o consumo de nutrientes e testar a adequabilidade do modelo nutricional SRNS para o consumo de matéria seca (CMS) e ganho médio diário (GMD) e as equações de Hankins e Howe para estimação da composição química da carcaça e do corpo vazio de 35 cordeiros Santa Inês, não castrados, com peso vivo médio inicial de 14,77 $\pm 1,26 \mathrm{Kg}$ e dois meses de idade. Após 10 dias de adaptação, cinco animais foram abatidos servindo como grupo referência para as estimativas do peso do corpo vazio (PCVZ) e da composição corporal inicial. Os animais remanescentes foram distribuídos em delineamento em blocos ao acaso com cinco tratamentos com diferentes níveis de energia metabolizável $(1,13 ; 1,40 ; 1,73 ; 2,22$ e $2,60 \mathrm{Mcal} / \mathrm{kg}$ de MS). Observou-se efeito quadrático para o CMS, expresso em g/d, \% PV e g/ $/ \mathrm{kg}^{0,75}$, com máximo consumo de MS de 867,25 g/d. Os consumos de carboidratos não fibrosos e nutrientes digestíveis totais, expressos em g/d, aumentaram linearmente com os níveis de EM e os consumos de fibra em detergente neutro, fibra em detergente ácido e carboidratos fibrosos, expressos em g/d, apresentaram efeito linear decrescente. O CMS e o GMD observado e o predito pelo modelo SRNS apresentou coeficiente de correlação de Pearson de 0,68 e 0,98 , respectivamente. Comparando a composição química da carcaça e da seção HH, observou-se que a seção HH estimou de forma satisfatória a composição de proteína e de extrato etéreo da carcaça de animais Santa Inês, com coeficiente de correlação de Pearson de 0,77 e 0,92 , respectivamente, enquanto o teor de água foi subestimado com coeficiente de correlação de Pearson de 0,42 . O corte das costelas também estimou satisfatoriamente os teores de extrato etéreo e proteína do corpo vazio ( $\mathrm{r}=0,96$ e 0,86 , respectivamente). Palavras-chave: Cordeiros, fibra, ingestão, ruminação, seção HH, SRNS
\end{abstract}

\footnotetext{
${ }^{1}$ Dissertação de mestrado, Universidade Federal do Ceará, Fortaleza.

${ }^{2}$ Discente de Mestrado, Programa de Mestrado em Zootecnia, Universidade Federal do Ceará, UFC, Fortaleza, CE. E-mail: ianaservulo@yahoo.com.br

${ }^{3}$ Prof $^{\mathrm{a}}$. Dr ${ }^{\mathrm{a}}$ do Dept ${ }^{\mathrm{o}}$ de Zootecnia, UFC, Fortaleza, CE. Bolsista de Produtividade do CNPq. E-mail: elzania@hotmail.com

${ }^{4}$ Prof $^{\text {s }}$ Dr $^{\text {as }}$ do Dept ${ }^{\mathrm{o}}$ de Zootecnia. UFC, Fortaleza, CE. E-mail: deiapp@hotmail.com; msocorro@ufc.br; anccampos11@gmail. com; crgadelha@yahoo.com.br

${ }^{5}$ Profs. Drs. do Dept ${ }^{\circ}$ de Zootecnia, Universidade Estadual de Londrina, UEL, Londrina, PR. E-mail: mizubuti@uel.br; elar@uel.br

${ }^{6}$ Zootecnista, Discente de Mestrado, UFC, Fortaleza, CE. E-mail: junior.nery@hotmail.com

* Autor para correspondência
} 


\begin{abstract}
The objective of this study was to evaluate the nutrient intake and suitability test of the SRNS nutritional model for dry matter intake (DMI) and average daily gain (ADG), and Hankins and Howe equations to estimate the carcass and empty body chemical composition of 35 Santa Ines lambs, non-castrated, with initial body weight of $14.77 \pm 1.26 \mathrm{~kg}$ and two months old. After 10 days of adaptation, five animals were slaughtered serving as reference group for estimates of empty body weight (EBW) and initial body composition. The remaining animals were distributed in randomized block design with five treatments with different levels of metabolizable energy $(1.13,1.40,1.73,2.22$ and $2.60 \mathrm{Mcal} / \mathrm{kg} \mathrm{DM})$. Quadratic effect was observed for DMI, expressed in $\mathrm{g} / \mathrm{d}, \% \mathrm{BW}$ and $\mathrm{g} / \mathrm{BW}^{0.75}$, with maximum DM intake of $867.25 \mathrm{~g} / \mathrm{d}$. Non fiber carbohydrates (NFC) and total digestible nutrients (TDN) intakes, expressed in $\mathrm{g} / \mathrm{d}$, increased with increases in ME levels and the intakes of neutral detergent fiber (NDF), acid detergent fiber (ADF) and fibrous carbohydrates (FC), expressed in $\mathrm{g} / \mathrm{d}$, presented decreasing linear effect. The DMI and ADG observed and predicted by SRNS model showed a Pearson correlation coefficient of 0.68 and 0.98 , respectively. Comparing the chemical composition of the carcass and $\mathrm{HH}$ section, observed that $\mathrm{HH}$ section estimated satisfactorily the protein and ether extract of carcass of animals, with Pearson correlation coefficient of 0.77 and 0.92 , respectively, while the water content was underestimated with Pearson correlation coefficient of 0.42 . The rib section also satisfactorily estimated to ether extract and protein in the empty body ( $\mathrm{r}=0.96$ and 0.86 , respectively).
\end{abstract}

Key words: Fiber, intake, lambs, rumination, section $\mathrm{HH}$, SRNS

\section{Introdução}

A suplementação concentrada é usada como estratégia para diminuir os impactos negativos da alimentação inadequada dos animais, aumentando a eficiência de utilização dos alimentos fornecidos e minimizando as perdas de nutrientes, uma vez que a alimentação representa uma fração significativa dos custos de produção (GALVANI, 2008). A alimentação, portanto, é um dos principais componentes que restringem a produção de carne ovina no nordeste do Brasil, e os ruminantes, como outras espécies, procuram ajustar o consumo alimentar às exigências nutricionais, especialmente em energia (ALVES et al., 2003).

Entretanto, se por alguma razão a natureza do volumoso disponível restringir o consumo alimentar, este limita também o desempenho animal, reduzindo a eficiência do processo produtivo, portanto, o consumo voluntário de matéria seca é uma variável importante que influencia o desempenho animal, podendo-se determinar, por meio dele, a quantidade de nutrientes ingeridos, além de se obter estimativas da quantidade de produto animal elaborado (PEREIRA et al., 2003). O consumo voluntário pode ser regulado por três mecanismos: o psicogênico, que envolve o comportamento do animal diante de fatores inibidores ou estimuladores relacionados ao alimento ou ao ambiente; o fisiológico, onde a regulação é dada pelo balanço nutricional, e o físico, relacionado com a capacidade de distensão do rúmen do animal (MERTENS, 1994).

Além do consumo, a determinação das exigências nutricionais dos animais é importante para a avaliação nutricional e desempenho do animal bem como para o balanceamento de rações de custo mínimo que atendam as suas necessidades nutricionais, visando à produção de carcaças mais ricas em músculos e com menos gordura, para, assim, atender as exigências do mercado consumidor (VÉRAS et al., 2001).

Para determinar as exigências nutricionais, o passo inicial consiste na mensuração da composição corporal dos animais. Os métodos utilizados para estimar a composição corporal são classificados como métodos diretos e indiretos. O método direto consiste da dissecação total de uma das meias-carcaças do animal, sendo um método caro e laborioso, que impede a comercialização dessa 
meia-carcaça, e os métodos indiretos envolvem a predição da composição corporal a partir de parâmetros mais facilmente obtidos (BACKES et al., 2002), sendo os mais utilizados, a gravidade específica e a seção entre a $9^{\mathrm{a}}$ e a $11^{\mathrm{a}}$ costelas (seção HH) da carcaça (VÉRAS et al., 2001).

O método indireto baseado no corte entre a $9^{\text {a }}$ e $11^{\mathrm{a}}$ costelas (HANKINS; HOWE, 1946) tem sido amplamente utilizado em bovinos, pois é um método rápido e barato, sendo alvo de validação para as condições brasileiras e para outras espécies de animais, por ter sido desenvolvido com animais taurinos (MARCONDES et al., 2009).

Desta forma, objetivou-se com este estudo avaliar o efeito de diferentes níveis de energia metabolizável das rações sobre o consumo de nutrientes, bem como testar a adequabilidade do modelo nutricional SRNS para o consumo de matéria seca (CMS) e ganho médio diário (GMD), e avaliar as equações de Hankins e Howe para estimar a composição química da carcaça e de corpo vazio (proteína, extrato etéreo e água) de cordeiros Santa Inês.

\section{Material e Métodos}

O experimento foi desenvolvido no Setor de Digestibilidade do Departamento de Zootecnia da Universidade Federal do Ceará, em Fortaleza, Ceará, no período de março a junho de 2011. O município de Fortaleza situa-se na zona litorânea, a $15,49 \mathrm{~m}$ de altitude, $30^{\circ} 43^{\prime}$ '02' de latitude sul e 38 32'35" de longitude oeste.

Foram utilizados 35 cordeiros da raça Santa Inês, não castrados, com peso vivo médio inicial de 14,77 $\pm 1,26 \mathrm{~kg}$ e, aproximadamente dois meses de idade. Inicialmente, os animais foram pesados, identificados, vermifugados e distribuídos em baias coletivas, providos de comedouro e água, fornecida ad libitum, por um período de 10 dias de adaptação. Após a adaptação, cinco animais foram escolhidos aleatoriamente e abatidos para servirem de controle para as estimativas de peso de corpo vazio (PCVZ) e para a composição corporal inicial dos 30 animais remanescentes, que foram alocados em baias individuais, providos de piso de concreto, com cama de maravalha, comedouro e bebedouros individuais, sendo metade dos animais em baias de alvenaria e metade em baias de madeira.

Os animais foram distribuídos em delineamento em blocos ao acaso com cinco tratamentos experimentais com diferentes níveis de energia metabolizável $(1,13 ; 1,40 ; 1,73 ; 2,22$ e 2,60 Mcal/ $\mathrm{kg}$ de MS), obtidos a partir de diferentes relações de volumoso:concentrado (100:0; 80:20; 60:40; 40:60; 20:80) e seis repetições. As dietas experimentais foram compostas de feno de Tifton 85 e concentrado à base de farelo de soja, fubá de milho, cloreto de sódio, ureia, calcário, fosfato bicálcico e premix mineral (Tabelas 1 e 2), sendo isoprotéicas (16\%) e formuladas segundo recomendações do NRC (2007) para categoria de animais em crescimento (acima de 4 meses) e ganho médio diário de $200 \mathrm{~g}$ / dia, exceto para o tratamento mantença.

$\mathrm{O}$ arraçoamento foi realizado duas vezes ao dia (8 e 16 horas), ajustado para permitir sobras em torno de $20 \%$ do fornecido e a água foi fornecida à vontade. Diariamente foram pesados e amostrados o alimento fornecido e as sobras, que foram acondicionadas em sacos plásticos, identificadas e armazenadas em freezer $\left(-10^{\circ} \mathrm{C}\right)$ para posterior análise, formando, ao final do experimento, uma amostra composta/tratamento/animal.

As amostras do volumoso, das rações concentradas e as amostras compostas das sobras foram pré-secas em estufa de ventilação forçada a $55 \pm 5^{\circ} \mathrm{C}$, durante $72 \mathrm{~h}$, e, em seguida, moídos em moinho de facas com peneira de $1 \mathrm{~mm}$. Foram determinados os teores de matéria seca (MS), matéria mineral $(\mathrm{MM})$, proteína bruta $(\mathrm{PB})$ e extrato etéreo (EE), conforme os procedimentos recomendados por Silva e Queiroz (2002); fibra em detergente neutro (FDN) e ácido (FDA) segundo Van Soest, Robertson e Lewis (1991); lignina (ácido sulfúrico 72 \%) pelo método sequencial de Van Soest e Robertson (1980) 
e nitrogênio insolúvel em detergente neutro (NIDN) e ácido (NIDA) de acordo com Licitra, Hernandez e Van Soest (1996). Para analisar a fibra em detergente neutro, as amostras foram tratadas com alfa amilase termoestável sem o uso de sulfito de sódio, corrigida para a cinza residual (MERTENS, 2002) e para residuais compostos nitrogenados (LICITRA; HERNANDES; VAN SOEST, 1996).

Tabela 1. Composição químico bromatológica dos ingredientes e dos concentrados experimentais.

\begin{tabular}{|c|c|c|c|c|c|c|c|}
\hline \multirow{2}{*}{ Nutrientes } & \multirow{2}{*}{$\begin{array}{l}\text { Feno de } \\
\text { tifton } 85\end{array}$} & \multirow{2}{*}{ Milho } & \multirow{2}{*}{ Soja } & \multicolumn{4}{|c|}{ Concentrado } \\
\hline & & & & 2 & 3 & 4 & 5 \\
\hline Matéria seca (MS, \%) & 92,00 & 88,61 & 88,10 & 87,64 & 87,96 & 88,22 & 88,85 \\
\hline Matéria orgânica (\% na MS) & 86,38 & 86,27 & 81,22 & 81,47 & 84,67 & 84,35 & 85,38 \\
\hline Proteína bruta (\% na MS) & 9,54 & 10,15 & 50,15 & 42,46 & 26,10 & 20,79 & 18,08 \\
\hline Extrato etéreo (\% na MS) & 1,85 & 3,67 & 2,35 & 1,37 & 3,18 & 2,78 & 3,40 \\
\hline Matéria mineral (\% na MS) & 5,62 & 2,34 & 6,88 & 6,17 & 3,29 & 3,87 & 3,47 \\
\hline $\mathrm{FDN}^{1}(\%$ na MS $)$ & 73,45 & 25,06 & 17,67 & 15,24 & 14,70 & 14,72 & 14,71 \\
\hline $\mathrm{FDNcp}^{2}(\%$ na MS $)$ & 66,83 & 22,84 & 15,71 & 13,67 & 13,16 & 13,49 & 12,98 \\
\hline $\mathrm{FDA}^{3}(\%$ na MS $)$ & 36,43 & 6,03 & 9,28 & 7,05 & 4,42 & 4,97 & 4,94 \\
\hline Lignina (\% na MS) & 3,41 & 0,95 & 1,64 & 1,08 & 0,79 & 0,90 & 1,01 \\
\hline Celulose (\% na MS) & 30,86 & 5,42 & 9,00 & 6,49 & 4,19 & 4,41 & 4,55 \\
\hline Hemicelulose (\% na MS) & 37,02 & 19,03 & 8,39 & 8,19 & 10,28 & 9,75 & 9,76 \\
\hline Carboidratos totais (\% na MS) & 82,99 & 83,85 & 40,62 & 55,44 & 69,70 & 74,59 & 75,97 \\
\hline $\mathrm{CNF}^{4}(\%$ na MS) & 16,16 & 61,01 & 24,91 & 41,77 & 56,54 & 61,10 & 62,90 \\
\hline $\mathrm{CF}^{5}(\%$ na $\mathrm{MS})$ & 66,83 & 22,84 & 15,71 & 13,67 & 13,16 & 13,49 & 12,98 \\
\hline
\end{tabular}

${ }^{1}$ Fibra em detergente neutro. ${ }^{2} \mathrm{FDN}$ corrigida para cinzas e proteína. ${ }^{3}$ Fibra em detergente ácido. ${ }^{4}$ Carboidratos não fibrosos. ${ }^{5}$ Carboidratos fibrosos.

Fonte: Elaboração dos autores.

Os teores de carboidratos totais (CT) foram obtidos conforme Sniffen et al. (1992): CT $(\%)=$ $100-(\% \mathrm{~PB}+\% \mathrm{EE}+\% \mathrm{MM})$ e os carboidratos não-fibrosos (CNF) segundo Weiss (1999): CNF $(\%)=100-(\% \mathrm{FDNcp}+\% \mathrm{~PB}+\% \mathrm{EE}+\% \mathrm{MM})$, onde FDNcp = fibra em detergente neutro corrigido para cinzas e proteínas. Devido à presença de uréia nos concentrados, os CNF destes foram calculados como proposto por Hall (2000): CNF (\%) = $100-$ $[(\% \mathrm{~PB}-\% \mathrm{~PB}$ derivada da uréia $+\%$ de uréia $)+$ $\% \mathrm{FDNcp}+\% \mathrm{EE}+\% \mathrm{MM}]$.

O tamanho de partícula das rações experimentais foi medido através do separador de partículas Penn State (SPPS) de acordo com metodologia citada por Kononoff e Heinrichs (2003). Foram pesadas aproximadamente $100 \mathrm{~g}$ das dietas experimentais, transferidas para o SPPS e submetidas a agitação manual, os alimentos foram separados em quatro tamanhos diferentes de partículas em função do diâmetro das peneiras $(1,18 ; 8$ e $19 \mathrm{~mm})$. O cálculo da estimativa de fibra em detergente neutro fisicamente efetiva (FDNfe) foi realizado de acordo com Mertens (1997), em que a concentração de FDN (\%MS) da ração foi multiplicada pela porcentagem de partículas retidas nas peneiras acima de 1,18 milímetros. FDNfe $>1,18=(\%$ de MS retida 1,18 milímetros) x \%FDN da ração/100.

Para determinação da energia metabolizável(EM) das rações realizou-se um ensaio de digestibilidade, utilizando a fibra em detergente neutro indigestível como indicador para estimar a produção de matéria seca fecal (CASALI et al., 2008). As fezes foram coletadas, diretamente da ampola retal, durante três dias consecutivos a cada 15 dias durante o período 
experimental, às 8:00 no primeiro dia, no meio-dia no segundo dia e às 16:00 horas do terceiro dia. A quantidade de FDNi nas amostras fecais, sobras, concentrados e feno Tifton- 85 foram obtidas através de incubações durante um período de 240 horas no rúmen de uma vaca. Após este período, as amostras foram lavadas com água até ficarem totalmente claras. Posteriormente, fervidas durante 1 hora em solução de detergente neutro (VAN SOEST; ROBERTSON; LEWIS, 1991), depois lavadas com água quente, em seguida com acetona, e, finalmente, secas em estufa de ventilação forçada a $55^{\circ} \mathrm{C}$ durante
24 horas e pesadas (CASALI et al., 2008). O NDT foi calculado de acordo com Weiss (1999): NDT $=\mathrm{PBd}+\mathrm{CNFd}+\mathrm{FDNcpd}+(\mathrm{EEd} \times 2,25)$; sendo $\mathrm{PBd}, \mathrm{CNFd}$, FDNcpd e EEd correspondente a: proteína bruta digestível, carboidratos não-fibrosos digestíveis, fibra em detergente neutro corrigido pra cinzas e proteínas digestível e extrato etéreo digestível, respectivamente. Considerou-se que 1 kg NDT contém 4,409 Mcal de energia digestível e para estimação da energia metabolizável das rações, considerou-se o valor de $82 \%$ da energia digestível (NRC, 1996).

Tabela 2. Composição percentual e químico bromatológica das rações experimentais.

\begin{tabular}{|c|c|c|c|c|c|}
\hline \multirow{2}{*}{$\begin{array}{c}\text { Composição percentual } \\
(\% \text { na MN) }\end{array}$} & \multicolumn{5}{|c|}{ Energia metabolizável (Mcal/kg MS) } \\
\hline & 1,13 & 1,40 & 1,73 & 2,22 & 2,60 \\
\hline Feno de Tifton & 100 & 80 & 60 & 40 & 20 \\
\hline Concentrado & 0 & 20 & 40 & 60 & 80 \\
\hline Fubá de milho ${ }^{1}$ & - & 15,87 & 69,45 & 72,46 & 75,61 \\
\hline Farelo de soja ${ }^{1}$ & - & 80,65 & 28,53 & 24,88 & 22,59 \\
\hline Ureia $^{1}$ & - & 3 & 1,25 & 1,12 & 0,51 \\
\hline Calcário ${ }^{1}$ & - & - & - & 0,54 & 0,66 \\
\hline Fosfato bicálcico $^{1}$ & - & - & - & - & 0,07 \\
\hline Cloreto de sódio ${ }^{1}$ & - & 0,4 & 0,7 & 0,93 & 0,5 \\
\hline Premix mineral $1^{1,2}$ & - & 0,08 & 0,07 & 0,07 & 0,06 \\
\hline \multicolumn{6}{|c|}{ Composição químico bromatológica } \\
\hline Matéria seca (MS, \%) & 92,00 & 91,13 & 90,38 & 89,73 & 89,48 \\
\hline Matéria orgânica (\% na MS) & 86,38 & 94,27 & 94,16 & 95,43 & 96,10 \\
\hline Proteína bruta (\% na MS) & 9,54 & 16,12 & 16,16 & 16,29 & 16,37 \\
\hline Extrato etéreo (\% na MS) & 1,85 & 1,75 & 2,38 & 2,41 & 3,09 \\
\hline $\mathrm{FDN}^{3}(\%$ na MS $)$ & 73,45 & 61,81 & 49,95 & 38,21 & 26,46 \\
\hline $\mathrm{FDNfe}^{4}(\%$ na MS $)$ & 69,04 & 50,68 & 38,96 & 26,75 & 13,23 \\
\hline $\operatorname{FDA}^{5}(\%$ na MS $)$ & 36,43 & 30,55 & 23,63 & 17,55 & 11,24 \\
\hline $\mathrm{FDNcp}^{6}(\%$ na MS $)$ & 66,83 & 56,20 & 45,36 & 34,83 & 23,75 \\
\hline Celulose (\% na MS) & 30,86 & 25,99 & 20,19 & 14,99 & 9,81 \\
\hline Hemicelulose (\% na MS) & 37,02 & 31,25 & 26,32 & 20,66 & 15,21 \\
\hline Carboidratos totais (\% na MS) & 82,99 & 77,48 & 77,67 & 77,95 & 77,37 \\
\hline $\mathrm{CNF}^{7}(\%$ na MS $)$ & 16,16 & 21,28 & 32,31 & 43,12 & 53,55 \\
\hline $\mathrm{NDT}^{8}(\%$ na MS) & 31,27 & 38,73 & 47,95 & 61,54 & 71,83 \\
\hline NDT:PB $9 \%$ na MS) & 3,28 & 2,40 & 2,97 & 3,78 & 4,39 \\
\hline
\end{tabular}

${ }^{1}$ Composição centesimal em relação à porção concentrada da dieta. ${ }^{2}$ Composição: Ca 7.5\%; P 3\%; Fe 16.500 ppm, Mn 9.750 ppm, Zn 35.000 ppm, I 1.000 ppm, Se 225 ppm, Co 1.000 ppm. ${ }^{3}$ Fibra em detergente neutro. ${ }^{4}$ FDN fisicamente efetiva. ${ }^{5}$ Fibra em detergente ácido. ${ }^{6} \mathrm{FDN}$ corrigida para cinzas e proteína. ${ }^{7}$ Carboidratos não-fibrosos. ${ }^{8}$ Nutrientes digestíveis totais. ${ }^{9}$ Relação entre nutrientes digestíveis totais e proteína bruta.

Fonte: Elaboração dos autores. 
O ganho médio diário foi obtido por meio das pesagens dos animais a cada semana. $\mathrm{O}$ abate dos animais foi realizado quando os animais atingiram uma média de $28 \mathrm{~kg}$ de peso corporal. Antes do abate, os animais foram pesados para obtenção do peso corporal anterior ao abate, em seguida, foram submetidos a jejum, de alimentos sólidos e água, por 18 horas e novamente pesados para obtenção do peso corporal ao jejum (PCj).

Por ocasião do abate, todo o sangue foi coletado, pesado, amostrado e congelado. O trato gastrintestinal (retículo, omaso, abomaso e intestino grosso e delgado) foi pesado cheio, em seguida esvaziado, lavado e escorrido a sombra. Posteriormente, todo o trato gastrintestinal foi novamente pesado, juntamente com os demais componentes do corpo (carcaça quente, cabeça, pele, patas e cauda). Os órgãos internos (fígado, coração, pulmões + traqueia + língua + esôfago, bexiga, rins, trato reprodutivo e baço), o trato gastrintestinal (rúmen, retículo, omaso, abomaso e intestino grosso e delgado) cheio e vazio, e gorduras (omental, mesentérica, perirrenal e gordura do coração) foram pesados separadamente. O peso de corpo vazio (PCVZ) foi calculado como sendo PCj subtraído o peso do conteúdo do trato gastrintestinal.

Após o abate, todas as carcaças foram pesadas quentes (cerca de $1 \mathrm{~h}$ após o abate) e colocadas em uma câmara fria $\left(-4^{\circ} \mathrm{C}\right)$ por cerca de 24 horas. Após a refrigeração, as carcaças foram pesadas novamente e, em seguida, separadas longitudinalmente em duas metades utilizando uma fita serra. Na meia-carcaça esquerda resfriada, retirou-se o corte da seção $\mathrm{HH}$, pela secção transversal da $9^{\mathrm{a}}-10^{\mathrm{a}}-11^{\mathrm{a}}$ costelas no ponto correspondente a $61,5 \%$ da distância entre a vértebra seccionada e o início da cartilagem da $12^{\text {a }}$ costela (HANKINS; HOWE, 1946).

As amostras foram moídas, em moedor de carne industrial, obtendo-se duas amostras por animal (massa moída dos órgãos + sangue + pés + cabeça e massa moída da meia carcaça direita). As amostras da pele foram cortadas em tiras e juntamente com a massa moída dos órgãos + sangue + pés + cabeça e meia carcaça direita foram pré-secas em estufa de ventilação forçada a $55^{\circ} \pm 5^{\circ} \mathrm{C}$ por 72 horas, em seguida trituradas em um multiprocessador. Após este procedimento, as amostras foram desengorduradas por meio de imersão em éter de petróleo em aparelho tipo Soxhlet (AOAC, 1990). Posteriormente, foram moídas em moinho de bola e armazenadas em recipientes fechados. Nas amostras desengorduradas determinaram-se os teores de matéria seca, cinzas e proteína bruta.

O modelo SRNS e a predição da composição corporal pela metodologia de Hankins e Howe (1946) foram avaliados quanto à sua precisão, utilizando o coeficiente de correlação de Pearson (r) e sua acurácia, ajustando a equação de regressão linear entre os valores preditos (variável independente) e observados (variável dependente). Os parâmetros da equação foram testados juntos na seguinte hipótese pelo teste F:

$$
\begin{array}{ll}
H_{0}: \beta_{0}=0 & H_{0}: \beta_{1}=1 \\
H_{0}: \beta_{0} \neq 0 & H_{0}: \beta_{1} \neq 1
\end{array}
$$

Para a não rejeição de ambas as hipóteses de nulidade, os valores preditos e observados são semelhantes, caso contrário, a tendência do modelo é subestimar ou superestimar a resposta do animal. O CMS ou GMD foi obtido por meio da divisão da diferença das médias da variável Y e X, pela média da variável X (TEDESCHI; FOX; RUSSELL, 2000).

Os dados estimados pela seção entre a $9^{\mathrm{a}}$ e $11^{\mathrm{a}}$ costelas e observados na carcaça e no peso de corpo vazio também foram comparados por meio de análise de regressão, de modo que $\mathrm{H}_{0}: \beta_{0}=0$ e $\beta_{1}=1$ e $\mathrm{H}_{\mathrm{a}}$ : não $\mathrm{H}_{0}$. Para o valor $\mathrm{P}$ menor de 0,05 detectouse diferença entre valores observados e estimados.

As análises estatísticas foram realizadas utilizando GLM PROC da versão SAS 9.0 (SAS, 2003), ao nível de significância de 5\%. O ajuste das equações de regressão linear, quadrático e cúbico foi obtido utilizando o PROC REG do SAS (9.0). 


\section{Resultados e Discussão}

Houve efeito quadrático (Tabela 3) com o incremento nos níveis de energia metabolizável (EM) sobre o consumo de matéria seca, expresso em $\mathrm{g} / \mathrm{d}, \% \mathrm{PV}$ e $\mathrm{g} / \mathrm{kg}^{0,75}$, com ponto de máximo consumo observado nos níveis de EM de 2,33; 1,93 e 2,04 $\mathrm{Mcal} / \mathrm{kg} \mathrm{MS}$, respectivamente. Em dietas com alta densidade energética, em relação aos requerimentos do animal, e baixo teor de fibra em detergente neutro (FDN), o consumo pode ser limitado pela demanda energética e não pela repleção ruminal, porém, em dietas com baixa densidade energética e alto conteúdo de FDN, o consumo pode ser limitado pelo enchimento do rúmen-retículo (MERTENS, 1987). Observou-se que na dieta sem concentrado, o controle físico limitou o consumo do animal em $582,87 \mathrm{~g} / \mathrm{d}$, equivalente a $3,2 \% \mathrm{PV}$ e $75,44 \mathrm{~g} / \mathrm{kg}^{0,75}$, havendo um aumento do consumo até o ponto de máxima inclusão de energia na dieta $(867,25 \mathrm{~g} / \mathrm{d})$, seguida de uma redução no consumo para 852,95 $\mathrm{g} / \mathrm{d}$ para o nível de EM na dieta de 2,60 Mcal/kg MS, corroborando com o exposto por Camilo et al. (2012), que salientam que o efeito quadrático no consumo de matéria seca em $\mathrm{g} / \mathrm{d}$, com o aumento dos níveis de energia na dieta, indicam a existência de um ponto de inflexão ou de transição entre o controle físico e biológico do consumo.

Tabela 3. Consumo de nutrientes em cordeiros da raça Santa Inês mantidos com rações com diferentes níveis de energia metabolizável.

\begin{tabular}{|c|c|c|c|c|c|c|c|c|}
\hline \multirow{2}{*}{ Ítem } & \multicolumn{5}{|c|}{ Energia metabolizável (Mcal/kg MS) } & \multirow{2}{*}{$\mathrm{R}^{2}$} & \multirow{2}{*}{$\mathrm{P}$} & \multirow{2}{*}{$\begin{array}{l}\text { CV } \\
(\%)\end{array}$} \\
\hline & 1,13 & 1,40 & 1,73 & 2,22 & 2,60 & & & \\
\hline \multicolumn{9}{|c|}{ Consumo $(\mathrm{g} / \mathrm{d})$} \\
\hline Matéria seca ${ }^{1}$ & 549,94 & 758,15 & 780,41 & 844,30 & 863,37 & 0,58 & 0,0139 & 11,33 \\
\hline Matéria orgânica ${ }^{2}$ & 457,76 & 667,88 & 711,18 & 790,54 & 831,05 & 0,71 & 0,0096 & 11,19 \\
\hline Proteína bruta ${ }^{3}$ & 56,89 & 148,21 & 148,28 & 156,41 & 158,04 & 0,69 & $<0,0001$ & 16,07 \\
\hline Extrato etéreo ${ }^{4}$ & 10,75 & 13,67 & 19,98 & 20,64 & 25,62 & 0,80 & $<0,0001$ & 13,85 \\
\hline Fibra em detergente neutro ${ }^{5}$ & 394,18 & 446,36 & 341,18 & 240,70 & 153,13 & 0,82 & $<0,0001$ & 16,04 \\
\hline Fibra em detergente ácido ${ }^{6}$ & 190,77 & 217,14 & 153,07 & 110,14 & 57,15 & 0,84 & $<0,0001$ & 17,87 \\
\hline Carboidratos totais $^{7}$ & 451,24 & 563,51 & 583,91 & 645,51 & 678,34 & 0,56 & $<0,0001$ & 10,98 \\
\hline Carboidratos fibrosos $^{8}$ & 356,84 & 405,37 & 309,68 & 222,60 & 146,34 & 0,81 & $<0,0001$ & 15,76 \\
\hline Carboidratos não-fibrosos ${ }^{9}$ & 94,40 & 158,14 & 274,23 & 422,91 & 537,33 & 0,97 & $<0,0001$ & 11,32 \\
\hline Nutrientes digestíveis totais ${ }^{10}$ & 172,08 & 293,60 & 374,96 & 520,11 & 621,38 & 0,88 & $<0,0001$ & 14,59 \\
\hline \multicolumn{9}{|c|}{ Consumo (\% PV) } \\
\hline Matéria seca ${ }^{11}$ & 3,67 & 4,21 & 4,30 & 4,39 & 4,08 & 0,30 & 0,0032 & 8,63 \\
\hline Fibra em detergente neutro ${ }^{12}$ & 2,63 & 2,66 & 1,88 & 1,25 & 0,72 & 0,93 & $<0,0001$ & 11,76 \\
\hline \multicolumn{9}{|c|}{ Consumo $\left(\mathrm{g} / \mathrm{kg}^{0,75}\right)$} \\
\hline Matéria seca $^{13}$ & 72,17 & 81,34 & 88,51 & 91,95 & 87,40 & 0,40 & 0,0012 & 8,01 \\
\hline Fibra em detergente neutro ${ }^{14}$ & 51,74 & 53,78 & 38,64 & 26,19 & 15,37 & 0,93 & $<0,0001$ & 11,67 \\
\hline
\end{tabular}

${ }^{1} \hat{\mathrm{Y}}=-204,22976+919,43035 \mathrm{EM}-197,23975 \mathrm{EM}^{2} ;{ }^{2} \hat{\mathrm{Y}}=-321,18218+930,55983 \mathrm{EM}-189,06134 \mathrm{EM}^{2} ;{ }^{3} \hat{\mathrm{Y}}=-255,29817+$ $394,83555 \mathrm{EM}-91,63768 \mathrm{EM}^{2} ;{ }^{4} \hat{\mathrm{Y}}=1,02411+9,44951 \mathrm{EM} ;{ }^{5} \hat{\mathrm{Y}}=660,24513-190,30575 \mathrm{EM} ;{ }^{6} \hat{\mathrm{Y}}=331,93808-102,79275 \mathrm{EM}$; ${ }^{7} \hat{\mathrm{Y}}=336,69760+136,28505 \mathrm{EM} ;{ }^{8} \hat{\mathrm{Y}}=590,97946-166,99036 \mathrm{EM} ;{ }^{9} \hat{\mathrm{Y}}=-258,99617+306,46634 \mathrm{EM} ;{ }^{10} \hat{\mathrm{Y}}=-141,32878+$ $296,00302 \mathrm{EM} ;{ }^{11} \hat{\mathrm{Y}}=0,68638+3,91356 \mathrm{EM}-1,00646 \mathrm{EM}^{2} ;{ }^{12} \hat{\mathrm{Y}}=4,37556-1,40534 \mathrm{EM} ;{ }^{13} \hat{\mathrm{Y}}=3,12379+88,46231 \mathrm{EM}-$ $21,65288 \mathrm{EM}^{2} ;{ }^{14} \hat{\mathrm{Y}}=86,24053-27,07177 \mathrm{EM}$.

Fonte: Elaboração dos autores. 
Além do nível de energia e teor de FDN, o tamanho das partículas das dietas experimentais também influencia o consumo do animal, portanto, a maior porcentagem de matéria seca retida na peneira com diâmetro de $19 \mathrm{~mm}$ (Tabela 4) para a dieta sem concentrado, pode ter contribuído com o menor consumo observado, influenciando na repleção ruminal, sendo que a diminuição no tamanho das partículas das dietas experimentais com o incremento dos níveis de energia metabolizável induziu um aumento no consumo de MS observado até o ponto de máxima inclusão de energia, havendo, a partir daí, uma redução no consumo devido a crescente quantidade de concentrado na dieta fazendo com que os animais atingissem suas demandas fisiológicas. De acordo com Poppi, Hendricksen e Minson (1985), o tamanho da partícula de $1,18 \mathrm{~mm}$ é que determina se uma partícula tem rápida $(<1,18 \mathrm{~mm})$ ou lenta $(>1,18 \mathrm{~mm})$ passagem pelo rúmen. A redução do tamanho de partícula e a ruptura da estrutura da parede celular aumentam a densidade do alimento permitindo uma taxa de digestão mais rápida, e menor volume ruminal, aumentando, consequentemente, o consumo de matéria seca.

Tabela 4. Distribuição das partículas (\%) nos ingredientes e nas rações experimentais.

\begin{tabular}{lrrrrr}
\hline \multirow{2}{*}{ DTM $^{1}$ (\% MS retida nas peneiras) } & \multicolumn{5}{c}{ Energia metabolizável (Mcal/kg MS) } \\
\cline { 2 - 6 } & 1,13 & 1,40 & 1,73 & 2,22 & 2,60 \\
\hline Acima de 19,0 mm & 68,00 & 44,00 & 38,00 & 18,00 & 10,00 \\
\hline $8,0-19,0 \mathrm{~mm}$ & 2,00 & 2,00 & 2,00 & 2,00 & 2,00 \\
$1,18-8,0 \mathrm{~mm}$ & 24,00 & 36,00 & 38,00 & 50,00 & 38,00 \\
Abaixo de 1,18 mm & 6,00 & 18,00 & 22,00 & 30,00 & 50,00 \\
\hline$>1,18 \mathrm{~mm}$ & 94,00 & 82,00 & 78,00 & 70,00 & 50,00 \\
\hline
\end{tabular}

${ }^{1}$ DTM $=$ distribuição do tamanho de partícula

Fonte: Elaboração dos autores.

Mertens (1994) destacou que a base para expressar consumo não é a mesma para os mecanismos físicos e fisiológicos de controle, sendo que, para rações de baixa qualidade, em que a ingestão é limitada pelo enchimento do rúmen, o ideal é expressá-lo em \% $\mathrm{PV}$, por se encontrar mais relacionado ao tamanho e a capacidade do trato digestório. Porém, quando o consumo é limitado pela demanda fisiológica de energia, a melhor forma de expressá-lo é com base no peso metabólico. Sendo assim, de acordo com as equações de regressão, os maiores consumos observados foram de 4,49 \% PV (1,93 Mcal de EM/ $\mathrm{kg}$ MS) e $93,48 \mathrm{~g} / \mathrm{kg}^{0,75}$ (2,04 Mcal de EM/kg MS)

Houve efeito linear $(\mathrm{P}<0,05)$ crescente dos níveis de energia metabolizável sobre os consumos de extrato etéreo, carboidratos não-fibrosos e nutrientes digestíveis totais expressos em g/d (Tabela 3).
Resultados semelhantes foram encontrados por Fontenele et al. (2011) estudando quatro níveis de energia metabolizável $(2,08 ; 2,28 ; 2,47$ e 2,69 $\mathrm{Mcal} / \mathrm{kg}$ de MS) na dieta de ovinos Santa Inês. Isso ocorreu devido a maior quantidade desses nutrientes à medida que aumentava a inclusão de concentrado na dieta.

Apesar do menor teor de carboidratos totais nas dietas (Tabela 2), também houve efeito linear crescente no consumo de carboidratos totais à medida que se aumentava a quantidade de concentrado nas dietas, isso ocorreu, provavelmente, devido à maior proporção de carboidratos não fibrosos, e, consequentemente, maior digestibilidade dos carboidratos totais, corroborando com os dados obtidos por Medeiros et al. (2007), que estudando o efeito de quatro níveis de concentrado (20;40; 
60 e $80 \%$ ) em rações de ovinos da raça Morada Nova, observaram aumento no consumo e na digestibilidade dos carboidratos totais com $\mathrm{o}$ aumento dos níveis de energia nas rações.

Os consumos de PB e MO, expressos em $\mathrm{g} / \mathrm{d}$, foram influenciados de forma quadrática pelo incremento nos níveis de energia na dieta (Tabela 3), refletindo o mesmo comportamento verificado para a ingestão de MS. Os consumos máximos estimados foram de 172,15 e 823,87 g/d, respectivamente, nos pontos de máxima inclusão de energia metabolizável de 2,15 e 2,46 Mcal/kg de MS, respectivamente. A elevação do consumo desses nutrientes até este nível pode ser explicada, entre outros fatores, pela demanda fisiológica do animal. A partir desses níveis, houve redução nos consumos de proteína bruta e matéria orgânica, que acompanharam a diminuição no consumo de matéria seca, como resultado do aumento da quantidade de concentrado ofertado, ou também pelo aumento na digestibilidade desses nutrientes. Resultado semelhante foram encontrados por Bringel et al. (2011) trabalhando com torta de dendê em substituição à silagem de capim elefante na alimentação de borregos, onde encontraram um consumo máximo de proteína e matéria orgânica, com o nível de inclusão de torta de dendê de 40,44 e 38,30\%, equivalente a 92,11 e $848,21 \mathrm{~g} / \mathrm{d}$, respectivamente.

Foi observado um efeito linear decrescente $(\mathrm{P}<0,05)$ sobre os consumos de carboidratos fibrosos (CF) e fibra em detergente ácido (FDA), em g/d, bem como sobre os consumos de FDN, expressos em $\mathrm{g} / \mathrm{d}, \% \mathrm{PV}$ e $\mathrm{g} / \mathrm{kg}^{0,75}$, com o aumento nos níveis de energia metabolizável nas dietas devido à redução da proporção de volumoso na dieta e consequentemente, redução no teor de fibra na matéria seca total das rações (Tabela 2), concordando com Mertens (1994) que explicou que quando a densidade energética da dieta é elevada (baixa concentração de FDN), em relação às exigências do animal, o consumo pode ser limitado pela demanda energética, não ocorrendo repleção ruminal. O mesmo resultado foi obtido por Alves et al. (2003) trabalhando com ovinos Santa Inês testando diferentes níveis de EM $(2,42$; 2,66; e 2,83 Mcal/kg de MS), onde observaram um consumo de FDN de 470,00; 330,00 e 210,00 g/d, respectivamente e, um efeito linear decrescente para o consumo de FDA quando os animais dispunham de níveis mais altos de energia na dieta. A utilização de um nível adequado de FDN na ração visa obter máxima produção, utilizando-se o máximo de volumoso sem, entretanto, provocar restrição na ingestão alimentar pelo efeito do enchimento do trato gastrintestinal, com consequente comprometimento do desempenho e elevação do tempo necessário para atingir o peso de abate (CARDOSO et al., 2006).

De acordo com os dados de CMS observado em função do CMS predito pelo modelo SRNS, obteve-se uma equação de regressão linear (Figura 1), apresentando um coeficiente de correlação de Pearson (r) igual a 0,68, correlação inferior à obtida por Costa (2012) que trabalhou com cordeiros Morada Nova alimentados com diferentes níveis energéticos, e obteve um coeficiente de correlação de Pearson de 0,86 para o CMS observado e predito pelo modelo SRNS. Segundo Poppi (2008), a variação do consumo de matéria seca representa a maior parte da diferença no ganho de peso e na produção animal, sendo considerado o fator de maior impacto na resposta animal.

O ganho médio diário (GMD) observado em função do valor predito pelo modelo SRNS mostrou alta precisão, apresentando uma equação de regressão linear e um coeficiente de correlação de Pearson igual a 0,96 (Figura 2). Esse fato pode ser atribuído a uma boa eficiência de utilização da energia metabolizável das dietas para o ganho de peso. O mesmo resultado foi observado por Linsky (2008) quando avaliou o SRNS e verificou que o GMD foi predito com acurácia e precisão. A hipótese de nulidade $(\mathrm{P}=0,24)$ não foi rejeitada para as duas variáveis. 
Figura 1. Relação entre o consumo de matéria seca (CMS) observado e predito pelo modelo SRNS em ovinos Santa Inês em crescimento.

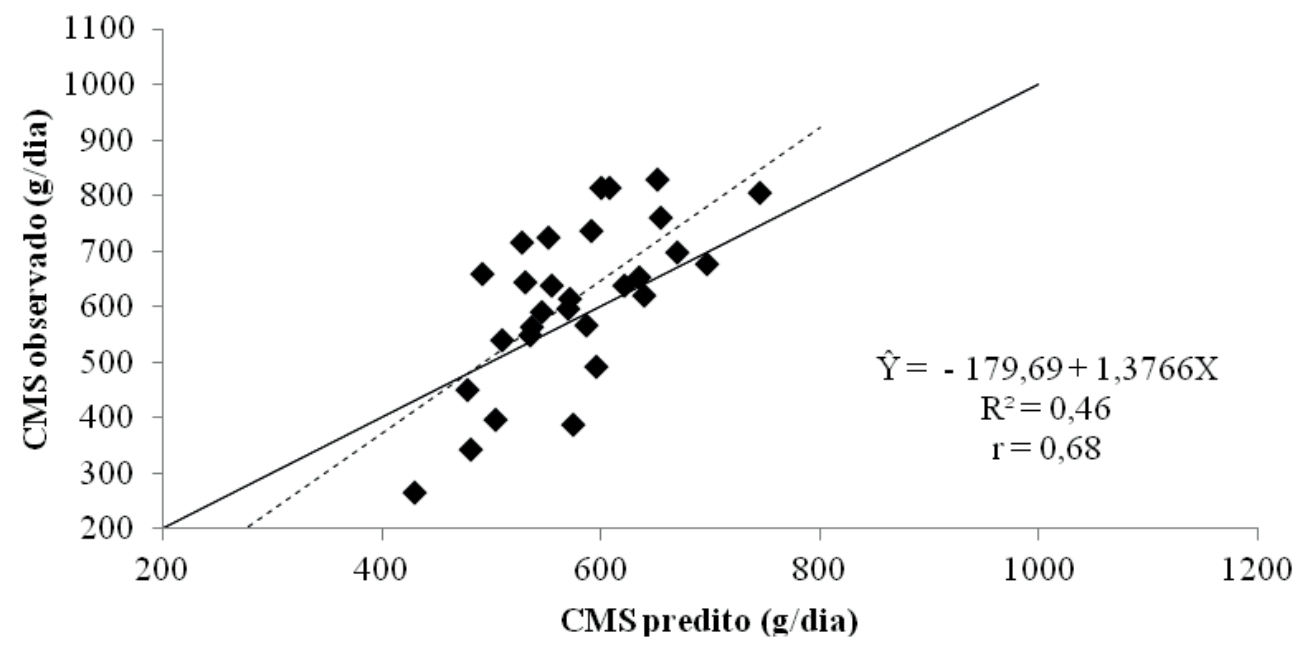

Fonte: Elaboração dos autores.

Figura 2. Relação entre o ganho médio diário de peso corporal (GMD) observado e predito pelo modelo SRNS em ovinos Santa Inês em crescimento.

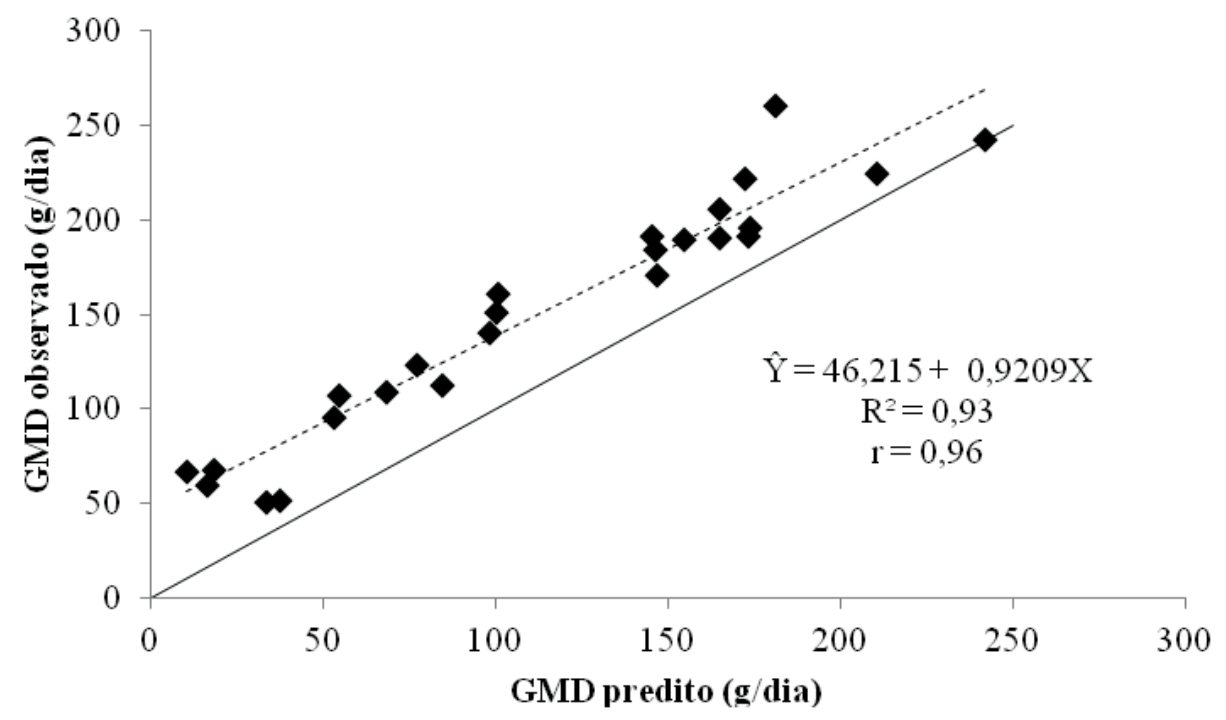

Fonte: Elaboração dos autores.

A seção HH permitiu estimar satisfatoriamente as porcentagens de extrato etéreo e proteína bruta (Tabela 5) nas carcaças dos animais, o que não foi observado para a composição de água. Segundo as análises estatísticas das regressões encontradas (Tabela 6) a hipótese de nulidade para estes componentes não foi rejeitada.
O teor de água da seção $\mathrm{HH}$ em relação ao teor na carcaça apresentou baixo valor para o coeficiente de correlação de Pearson (r), igual a 0,42 , entretanto, para os teores de extrato etéreo e proteína bruta, a composição da seção $\mathrm{HH}$ mostrou-se satisfatória para estimativa de seus teores na carcaça, com valores de $r=0,92$ e $r=$ 
0,77, respectivamente. Segundo Marcondes et al. (2009) para estimação indireta da composição química do animal, são necessárias equações que à estimem a partir da composição química da seção HH. Algumas pesquisas no Brasil já foram realizadas com esse intuito, para bovinos, e algumas equações foram desenvolvidas (HENRIQUE et al., 2003; PAULINO et al., 2005), no entanto, são necessários mais trabalhos para a validação dessas equações.

Tabela 5. Estimativa dos parâmetros, valores descritivos de probabilidade para as hipóteses de nulidade, coeficientes de determinação $\left(\mathrm{R}^{2}\right)$ e coeficiente de correlação de Pearson (r) para os valores estimados e observados das porcentagens de extrato etéreo (EE), proteína bruta (PB) e água.

\begin{tabular}{lcccccc}
\hline \multirow{2}{*}{ Itens } & \multicolumn{9}{c}{ Regressão } \\
\cline { 2 - 5 } & \multicolumn{2}{c}{ Intercepto } & \multicolumn{2}{c}{ Coeficiente de inclinação } & & \\
\cline { 2 - 6 } & Estimativa & Valor P & Estimativa & Valor P & $\mathrm{R}^{2}$ & $\mathrm{r}$ \\
\hline Extrato etéreo & $-5,424$ & 0,001 & 1,385 & $<0,001$ & 0,85 & 0,92 \\
Proteína bruta & 1,845 & 0,459 & 0,828 & $<0,001$ & 0,78 & 0,77 \\
Água & 51,498 & 0,0006 & 0,205 & 0,3467 & 0,03 & 0,42 \\
\hline
\end{tabular}

Fonte: Elaboração dos autores.

Para os valores de extrato etéreo e proteína bruta, os teores médios obtidos por meio da análise direta da carcaça e da seção HH apresentaram-se bem próximas com variação de $1,16 \%$ e $7,90 \%$, respectivamente, podendo, para estes componentes da carcaça, o valor obtido pelo método indireto ser utilizado com eficiência e acurácia (Figura 3).

Mesmo o valor médio do teor de água na carcaça estando próximo ao valor obtido da seção $\mathrm{HH}$, com uma variação de 2,15\% (Tabela 6), o valor deste componente na carcaça não pode ser substituído pelo valor estimado por meio da seção entre a $9^{\mathrm{a}}$ e a $11^{\mathrm{a}}$ costelas em virtude da grande dispersão entre os valores obtidos (Figura 3 ) resultando em um baixo valor para o coeficiente de determinação $\left(\mathrm{R}^{2}=0,03\right)$. A baixa correlação entre o teor de água na carcaça e na seção $\mathrm{HH}$ pode estar relacionada com o efeito da raça sobre estas variáveis.

Tabela 6. Médias e amplitudes de variação para as porcentagens de extrato etéreo, proteína bruta e água na carcaça dos animais e na seção HH.

\begin{tabular}{|c|c|c|}
\hline Componente & Composição da carcaça & Composição da seção HH \\
\hline & \multicolumn{2}{|c|}{ Extrato etéreo } \\
\hline Média (\%) & 14,53 & 14,70 \\
\hline Desvio padrão (\%) & 4,10 & 6,16 \\
\hline \multirow[t]{2}{*}{ Amplitude de variação (\%) } & $20,63-4,24$ & $22,81-5,16$ \\
\hline & \multicolumn{2}{|c|}{ Proteína bruta } \\
\hline Média (\%) & 19,88 & 18,31 \\
\hline Desvio padrão (\%) & 2,64 & 2,86 \\
\hline \multirow[t]{2}{*}{ Amplitude de variação (\%) } & $26,74-16,49$ & $24,21-14,38$ \\
\hline & \multicolumn{2}{|c|}{ Água } \\
\hline Média (\%) & 63,04 & 64,43 \\
\hline Desvio padrão (\%) & 3,09 & 2,51 \\
\hline Amplitude de variação (\%) & $69,97-59,67$ & $70,13-59,23$ \\
\hline
\end{tabular}

Fonte: Elaboração dos autores. 
Com base nos teores de gordura, proteína e água da seção $\mathrm{HH}$, estimou-se a composição do corpo vazio de cordeiros Santa Inês (Tabela 7). Os valores para os teores de extrato etéreo e proteína do corpo vazio obtido por meio da composição da carcaça e os valores estimados utilizando a composição da seção HH mostraram-se altamente correlacionados (Figura 4), com os valores do coeficiente de correlação de Pearson (r) igual a 0,96 e 0,86, respectivamente. Trabalhos com bovinos mostram resultados semelhantes, Peron et al. (1993) verificaram correlações significativas de 0,93 e 0,99 para proteína e gordura, respectivamente.

Figura 3. Relação entre os teores de extrato etéreo (EE), proteína bruta (PB) e água observados na carcaça e na seção HH.
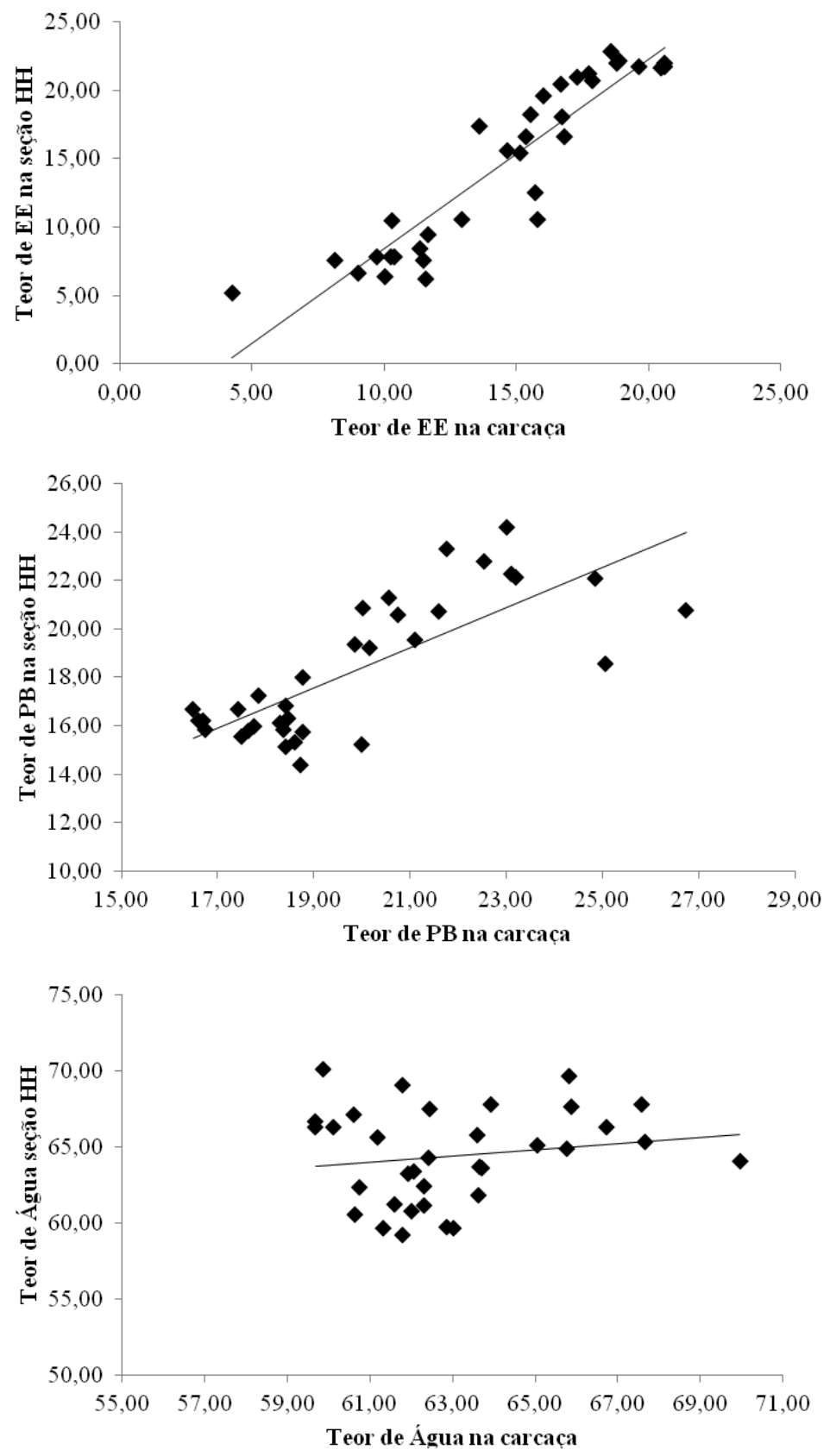

Fonte: Elaboração dos autores. 
Figura 4. Relação entre os teores de nutrientes observados no corpo vazio e estimados por meio da seção HH.
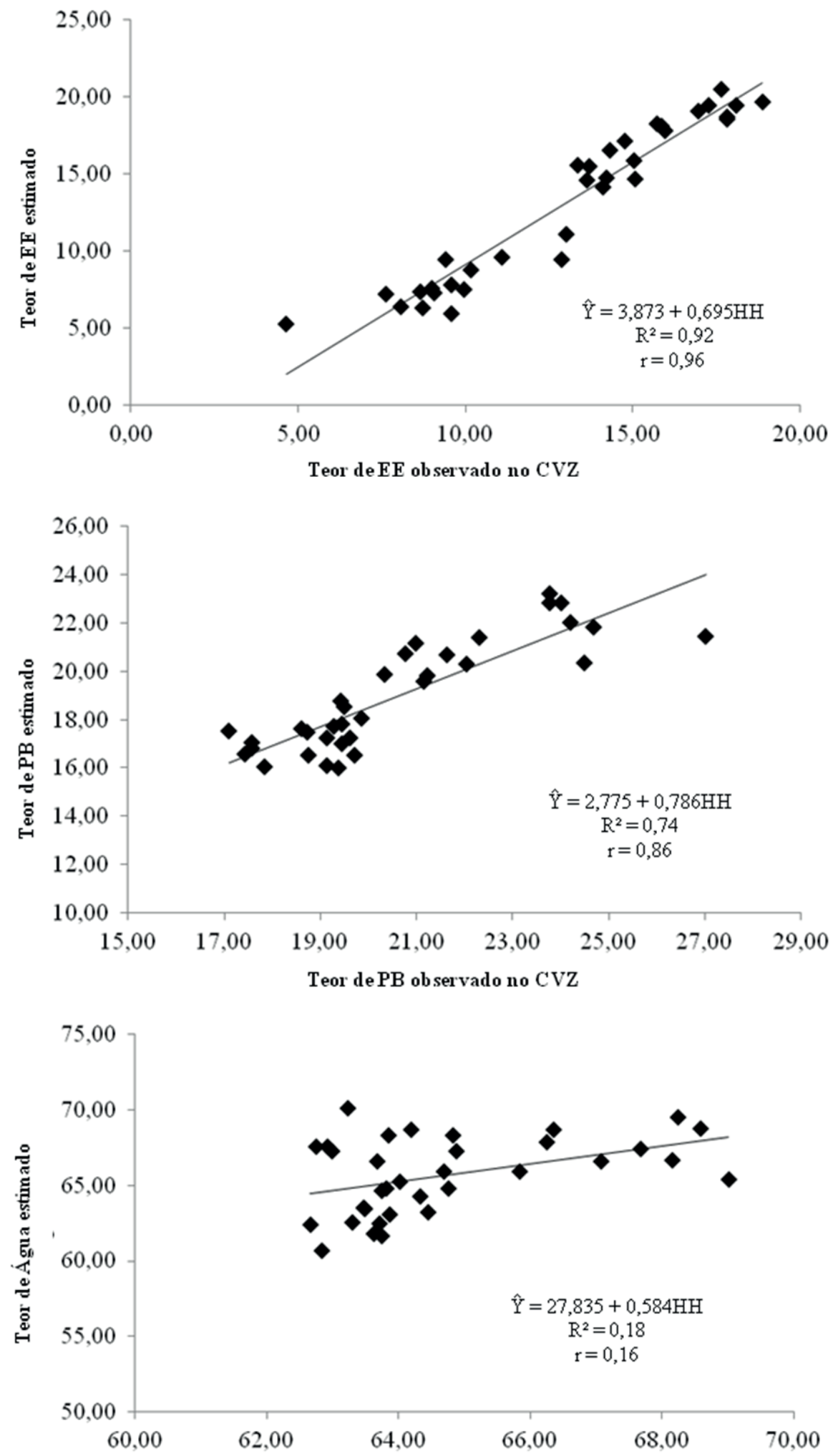

Teor de Água observado no CVZ

Fonte: Elaboração dos autores. 
Para obtenção das equações de predição da do CVZ e da seção HH. A equação gerada não composição química do corpo vazio (CVZ), refletiu grau alto de precisão para o teor de água realizou-se uma regressão linear entre a composição $(\mathrm{r}=0,16)$ tanto quanto o obtido para os demais constituintes (Tabela 7).

Tabela 7. Relações entre os componentes químicos observados no corpo vazio e estimados por meio da seção HH em cordeiros Santa Inês.

\begin{tabular}{llccc}
\hline \multicolumn{1}{c}{ Componentes } & Equação de regressão & Erro padrão da média & $\mathrm{R}^{2}$ & $\mathrm{R}$ \\
\hline Extrato etéreo & $\hat{\mathrm{Y}}=3,873+0,695 \mathrm{HH}$ & 1,04 & 0,92 & 0,96 \\
Proteína bruta & $\hat{\mathrm{Y}}=2,775+0,786 \mathrm{HH}$ & 1,15 & 0,74 & 0,86 \\
Água & $\hat{\mathrm{Y}}=27,835+0,584 \mathrm{HH}$ & 2,33 & 0,18 & 0,16 \\
\hline
\end{tabular}

Fonte: Elaboração dos autores.

Os valores dos teores de extrato etéreo, proteína e água do CVZ estimados utilizando a composição química da seção $\mathrm{HH}$ foram próximos aos valores observados quando se utilizou a composição química da carcaça para determinação do conteúdo corporal do CVZ (Tabela 8), com variações de $+0,92 ;-7,92$ e $+1,42 \%$, respectivamente, entre os valores médios estimados e os observados. Mesmo com essa pequena variação $(+1,42 \%)$ para os valores médios do teor de água estimados e observados, a estimativa do teor de água no CVZ por meio da composição da seção HH não foi satisfatória em virtude da grande dispersão dos valores observados e preditos (Figura 4), resultando em um baixo coeficiente de determinação $\left(\mathrm{R}^{2}=0,18\right)$ e de correlação de Pearson $(\mathrm{r}=0,16)$. Ao contrário, Henrique et al. (2003) observaram que o teor de água no corpo vazio foi altamente correlacionada com o teor de água no corte da costela para tourinhos Santa Gertrudes.

Tabela 8. Médias e amplitudes de variação para as porcentagens de extrato etéreo, proteína bruta e água no corpo vazio observado e estimado por meio da seção HH.

\begin{tabular}{|c|c|c|}
\hline Componente & Composição observada & Composição estimada \\
\hline & \multicolumn{2}{|c|}{ Extrato etéreo } \\
\hline Média (\%) & 12,99 & 13,11 \\
\hline Desvio padrão (\%) & 3,70 & 5,12 \\
\hline \multirow[t]{2}{*}{ Amplitude de variação (\%) } & $18,87-4,65$ & $20,54-5,28$ \\
\hline & \multicolumn{2}{|c|}{ Proteína bruta } \\
\hline Média (\%) & 20,59 & 18,96 \\
\hline Desvio padrão (\%) & 2,46 & 2,24 \\
\hline \multirow[t]{2}{*}{ Amplitude de variação (\%) } & $27,02-17,10$ & $23,20-15,98$ \\
\hline & \multicolumn{2}{|c|}{ Água } \\
\hline Média (\%) & 64,74 & 65,66 \\
\hline Desvio padrão (\%) & 1,84 & 2,53 \\
\hline Amplitude de variação (\%) & $69,01-62,66$ & $70,06-60,64$ \\
\hline
\end{tabular}

Fonte: Elaboração dos autores. 
A seção entre a $9^{\mathrm{a}}$ e a $11^{\mathrm{a}}$ costelas tem sido amplamente utilizada para estimar a composição corporal da carcaça e do corpo vazio (HANKINS; HOWE, 1946) em bovinos. As equações ajustadas para os teores de extrato etéreo e proteína do corpo vazio, em função dos teores desses mesmos constituintes na seção $\mathrm{HH}$, apresentaram elevados coeficientes de determinação e reduzido erropadrão da estimativa, permitindo inferir, com alto grau de precisão, que é possível estimar a composição corporal a partir do corte entre a $9^{\mathrm{a}}$ e a $11^{\text {a }}$ costelas de cordeiros Santa Inês, corroborando com o resultado descrito por Paulino et al. (2005) para bovinos mestiços Nelore x Bos taurus.

\section{Conclusão}

O consumo de nutrientes de cordeiros da raça Santa Inês na fase de crescimento é influenciado pelo aumento dos níveis de energia metabolizável das rações.

O modelo SRNS mostra alta correlação para as variáveis, consumo de matéria seca e ganho médio diário de cordeiros Santa Inês.

As equações propostas pelo método indireto (seção HH) são eficientes para estimar com precisão a composição de extrato etéreo e proteína bruta da carcaça e de corpo vazio de cordeiros Santa Inês.

\section{Agradecimentos}

Ao Banco do Nordeste do Brasil pelo suporte financeiro para a realização desse trabalho de pesquisa.

\section{Referências}

ALVES, K. S.; CARVALHO, F. F. R.; VÉRAS, A. S. C.; ANDRADE, M. F.; COSTA, R. G.; BATISTA, A. M. V.; MEDEIROS, A. N.; MAIOR JUNIOR, R. J. S.; ANDRADE, D. K. B. Níveis de energia para ovinos Santa Inês: Desempenho. Revista Brasileira de Zootecnia, Viçosa, MG, v. 32, n. 6, p. 1937-1944, 2003. Suplemento 2.
ASSOCIATION OF OFFICIAL ANALYTICAL CHEMISTS - AOAC. Official methods of analysis of AOAC international. 14. ed. Washington, DC.: AOAC, 1990. $1094 \mathrm{p}$.

BACKES, A. A.; SANCHEZ, L. M. B.; GONÇALVES, M. B. F.; PIRES, C. C. Composição corporal e exigências líquidas de energia e proteína para ganho de peso de novilhos santa gertrudis. Revista Brasileira de Zootecnia, Viçosa, MG, v. 31, n. 6, p. 2307-2313, 2002.

BRINGEL, L. M. L.; NEIVA, J. N. M.; ARAÚJO, V. L.; BONFIM, M. A. D.; RESTLE, J.; FERREIRA, A. C. H.; LÔBO, R. N. B. Consumo, digestibilidade e balanço de nitrogênio em borregos alimentados com torta de dendê em substituição à silagem de capim-elefante. Revista Brasileira de Zootecnia, Viçosa, MG, v. 40, n. 9, p. 19751983, 2011.

CAMILO, D. A.; PEREIRA, E. S.; PIMENTEL, P. G.; OLIVEIRA, R. S.; CÂNDIDO, M. J. D.; COSTA, M. R. G. F.; AQUINO, R. M. S. Intake and feeding behavior of Morada Nova lambs fed different energy levels. Italian Journal of Animal Science, Pavia, v. 11, n. 3, p. 13-19, 2012.

CARDOSO, A. R.; CARVALHO, S.; GALVANI, D. B.; PIRES, C. C.; GASPERIN, B. G.; GARCIA, R. P. A. Comportamento ingestivo de cordeiros alimentados com dietas contendo diferentes níveis de fibra em detergente neutro. Ciência Rural, Santa Maria, v. 36, n. 2, p. 604609, 2006.

CASALI, A. O.; DETMANN, E.; VALADARES FILHO, S. C.; PEREIRA, J. C.; HENRIQUES, L. T.; FREITAS, S. G.; PAULINO, M. F. Influência do tempo de incubação e do tamanho de partículas sobre os teores de compostos indigestíveis em alimentos e fezes bovinas obtidos por procedimentos in situ. Revista Brasileira de Zootecnia, Viçosa, MG, v. 37, n. 2, p. 335-342, 2008.

COSTA, M. R. G. F. Exigências nutricionais de cordeiros deslanados e validação do modelo Small Ruminantion Nutrition System (SRNS). 2012. Tese (Doutorado em Zootecnia) - Universidade Federal do Ceará, Fortaleza.

FONTENELE, R. M.; PEREIRA, E. S.; CARNEIRO, M. S. S; PIMENTEL, P. G.; CÂNDIDO, M. J. D.; REGADAS FILHO, J. G. L. Consumo de nutrientes e comportamento ingestivo de cordeiros da raça Santa Inês alimentados com rações com diferentes níveis de energia metabolizável. Revista Brasileira de Zootecnia, Viçosa, MG, v. 40, n. 6, p. 1280-1286, 2011.

GALVANI, D. B. Exigências e eficiências de utilização da energia e da proteina por cordeiros confinados. 2008. Dissertação (Mestrado em Zootecnia) - Universidade Federal de Santa Maria, Santa Maria. 
HALL, M. B. Calculation of non-structural carbohydrate content of feeds that contain non-protein nitrogen. Gainesville: University of Florida, 2000. p. 25. (Bulletin, 339).

HANKINS, O. G.; HOWE, P. E. Estimation of the composition of beef carcasses and cuts. Washington: United States Department of Agriculture, 1946. p. 1-19. (Technical Bulletin, 926).

HENRIQUE, W.; SAMPAIO, A. A. M.; LEME, P. R.; ALlEONI, G. F.; LANNA, D. P. D. Estimativa da composição química corporal de tourinhos Santa Gertrudis a partir da composição química e física das $9^{\mathrm{a}}-10^{\mathrm{a}}-11^{\mathrm{a}}$ costelas. Revista Brasileira de Zootecnia, Viçosa, MG, v. 32, n. 3, p. 709-718, 2003.

KONONOFF, P. J., HEINRICHS, A. J. The effect of reducing alfafa haylage particle size on cows in early lactation. Journal of Dairy Science, Savoy, v. 86, n. 4, p. 1445-1457, 2003.

LICITRA, G.; HERNANDES, T. M.; VAN SOEST, P. J. Standardization of procedures for nitrogen fractionation of ruminant's feeds. Animal Feed Science and Technology, Amsterdam, v. 57, n. 4, p. 347-358, 1996.

LINSKY, A. Evaluation of the small ruminant nutrition system for early and late maturing sheepbreeds under Southern African conditions. Pretoria, South Africa: University of Pretoria, 2008. 153 p.

MARCONDES, M. I.; VALADARES FILHO, S. C.; PAULINO, P. V. R.; DETMANN, E.; VALADARES, R. F. D.; SANTOS, T. R.; DINIZ, L. L. Predição da composição corporal e da carcaça a partir da seção entre a $9^{\mathrm{a}}$ e $11^{\mathrm{a}}$ costelas em bovinos Nelore. Revista Brasileira de Zootecnia, Viçosa, MG, v. 38, n. 8, p. 1597-1604, 2009.

MEDEIROS, G. R.; CARVALHO, F. F. R.; FERREIRA, M. A.; BATISTA, A. M. V.; ALVES, K. S.; MAIOR JÚNIOR, R. J. S.; ALMEIDA, S. C. Efeito dos níveis de concentrado sobre o desempenho de ovinos Morada Nova em confinamento. Revista Brasileira de Zootecnia, Viçosa, MG, v. 36, n. 4, p. 1162-1171, 2007. Suplemento.

MERTENS, D. R. Creating a system for meeting the fibre requirements of dairy cows. Journal of Dairy Science, Savoy, v. 80, n. 7, p. 1463-1481, 1997.

Gravimetric determination of amylase-treated $\overline{\text { neutral }}$ detergent fiber in feeds with refluxing in beaker or crucibles: collaborative study. Journal of $A O A C$ International, Gaithersburg, v. 85, n. 6, p. 1217-1240, 2002.

Predicting intake and digestibility using mathematical models of ruminal function. Journal of
Animal Science, Champaign, v. 64, n. 5, p. 1548-1558, 1987.

Regulation of forage intake. In: FAHEY JUNIOR, G. C. (Ed.). Forage quality, evaluation and utilization. Madison: American Society of Agronomy, 1994. p. 450-493.

NATIONAL RESEARCH COUNCIL - NRC. Nutrient requirements of beef cattle. 6. ed. Washington, DC.: National Academy Press, 1996. 234 p.

Nutrient requirements of sheep. 7. ed. Washington: National Academic Press, 2007. 99 p.

PAULINO, P. V. R.; COSTA, M. A. L.; VALADARES FILHO, S. C.; PAULINO, M. F.; VALADARES, R. F. D.; MAGAlHÃES, K. A.; DETMAN, E.; PORTO, M. O.; MORAES, K. A. K. Validação das equações desenvolvidas por Hankins e Howe para predição da composição da carcaça de zebuínos e desenvolvimento de equações para estimativa da composição corporal. Revista Brasileira de Zootecnia, Viçosa, MG, v. 34, n. 1, p. 327-339, 2005.

PEREIRA, E. S.; ARRUDA, A. M. V.; MIZUBUTI, I. Y.; SILVA, L. D. F. Consumo voluntário em ruminantes. Semina: Ciências Agrárias, Londrina, v. 24, n. 1, p. 191196, 2003.

PERON, A. J.; FONTES, C. A. A.; LANA, R. P.; QUEIROZ, A. C.; SILVA, D. J.; FREITAS, J. A. Predição da composição corporal e da carcaça de bovinos através de métodos indiretos. Revista Brasileira de Zootecnia, Viçosa, MG, v. 22, n. 2, p. 227-237, 1993.

POPPI, D. P. The dilemma in models of intake regulation: mechanistic or empirical. In: FRANCE, J.; KEBREAB, E. (Ed.). Mathematical modelling in animal nutrition. Wallingford: CAB International, 2008. p. 121-141.

POPPI, D. P.; HENDRICKSEN, R. E.; MINSON, D. $\mathrm{J}$. The relative resistance to escape of leaf and stem particles from the rumen of cattle and sheep. Journal of Agricultural Sciences, Canadá, v. 105, n. 1, p. 9-14, 1985.

SILVA, D. J.; QUEIROZ, A. C. Análises de alimentos: métodos químicos e biológicos. 3. ed. Viçosa: Editora UFV, 2002. $235 \mathrm{p}$.

SNIFFEN, C. J.; O’CONNOR, J. D.; VAN SOEST, P. J.; FOX, D. G.; RUSSELL, J. B. A net carbohydrate and protein system for evaluating cattle diets: II. Carbohydrate and protein availability. Journal of Animal Science, Champaign, v. 70, n. 10, p. 3562-3577, 1992.

STATISTICAL ANALYSIS SYSTEM - SAS. SAS system for windows: version 9.0. SAS Institute, Cary, NC, 2003. 
TEDESCHI, L. O.; FOX, D. G.; RUSSELL, J. B. Accounting for the effects of a ruminal nitrogen deficiency within the structure of the cornell net carbohydrate and protein system. Journal of Animal Science, Champaign, v. 78 , n. 6, p. 1648-1658, 2000.

VAN SOEST, J. P.; ROBERTSON, J. B. Systems of analysis for evaluating fibrous feed. In: PIGDEN, W. J.; BALCH, C. C.; GRAHAM, M. (Ed.). Standardization of analytical methodology for feeds. Ottawa: International Development Research Center, 1980. p. 49-60.

VAN SOEST, P. J.; ROBERTSON, J. B.; LEWIS, B. A. Symposium: carbohydrate methodology, metabolism, and nutritional implications in dairy cattle. Journal of Dairy Science, Savoy, v. 74, n. 10, p. 3583-3597, 1991.
VÉRAS, A. S. C.; VALADARES FILHO, S. C.; SILVA, J. F. C.; PAULINO, M. F.; CECON, P. R.; VALADARES, R. F. D.; FERREIRA, M. A.; SILVA, C. M.; SILVA, B. C. Predição da composição corporal de bovinos Nelore e F1 Simental x Nelore a partir da composição química da seção Hankins e Howe (Seção HH). Revista Brasileira de Zootecnia, Viçosa, v. 30, n. 3, p. 1112-1119, 2001.

WEISS, W. P. Energy prediction equations for ruminant feeds. In: CORNELL NUTRITION CONFERENCE FOR FEED MANUFACTURES, 61., 1999, Ithaca. Proceedings... Ithaca: Cornell University, 1999. p. 176185. 
